\title{
OVERCOMING DISAGREEMENT THROUGH ORDERING: BUILDING AN EPISTEMIC HIERARCHY
}

\begin{abstract}
This paper begins with an assessment of the origin of the term 'deep disagreement' to reflect fundamental differences in argument procedure and suggests an alternative explanation of such stalemates that may apply in many cases and does lead to a possible resolution strategy, through discussion of the ordering of certain principles, rather than their acceptance or rejection. Similarities are then drawn with disputes which are supported by conflicting expert opinions and I lay out the advantages of seeking to resolve them through the construction of an epistemic hierarchy. It is noted that while such hierarchies may not be easy to build, and are certainly not fool-proof, their importance is in the provision of a mechanism by which an apparently stalled debate can move forward, leading to a better understanding of the conflicting positions, if not full resolution.
\end{abstract}

Keywords: deep disagreement, Fogelin, epistemic hierarchy, appeal to expert opinion.

\section{Deep Disagreement}

Like much of the best academic work, Robert Fogelin's paper on deep disagreement is short and leaves it to others to discuss and debate the implications of what he has to say. Indeed, only half the paper actually discusses disagreement at all, with the first section introducing the idea that argument involves an accepted set of background assumptions, that those involved 'share a great many beliefs and (if this is different) a great many preferences [which] lie in the background, unmentioned' (Fogelin 2005: 5). This situation Fogelin refers to as 'normal', which leads him to ask what happens when it doesn't obtain and suggest that 'to the extent that the argumentative context becomes less normal, argument, to that extent, become impossible' (2005: 7): that is to say, we have deep disagreement, to some extent, at least, or, perhaps, disagreement to some depth. 
It is my intention to follow Fogelin's lead in being brief. I shall begin with a short discussion of his examples and what we can learn from them and from there move on to the example of arguments from expert opinion and more generally from testimony, to show how they relate to the difficulties Fogelin cites in his paper.

Fogelin gives two examples of deep disagreements and then notes the obvious similarity between them. First he describes a debate over abortion where the disagreement is not caused by generally opposed moral frameworks, since everyone agrees it's wrong to kill people, but over the status of the foetus - is it a person or not? While this looks like a question which might be answered by scientific investigation, it soon becomes clear that it isn't. What is at stake is not whether the foetus is like us only smaller it clearly isn't - nor whether it is of the human species - it clearly is. The question is whether or not an unborn child has moral status as a human, and, if so, when does it acquire that status.

The second example considers affirmative action quotas, or positive discrimination. Here again, the issue is not whether certain individuals have been treated unfairly and others have taken advantage of that, such examples are easy to find, but whether this injustice can be somehow righted by treating unfairly individuals who happen to belong to the same group as those who gained previously, and giving an advantage to others who happen to belong to the earlier disadvantaged group. This problem affects not only race relations, but also questions of gender balance, and it lies at the heart of a good deal of aggressive nationalism and calls for various types of reparations. Fogelin notes that this is a dispute 'concerning moral standing' (2005: 10), and that it is similar in that to the abortion case, but draws no further conclusions from that similarity.

I would suggest that the fact that both his examples boil down to exactly the same dispute is of some significance. In the first example, one side assigns moral rights to a foetus, the other denies them. In the second, one side assigns moral rights to a group (however defined), and the other denies them. We might easily conclude that deep disagreements are ones which refer to moral questions, but something subtler is at play here: two people may very well believe in just treatment for all, regardless of gender, race etc., and still disagree over the assignment of rights to groups; another two may agree over the sanctity of human life, but argue about abortion. Both debates centre not on what is good and right, but on who or what has rights. That question is fundamental in many of the greatest public debates of our, and perhaps any, times: Do future generations have the right to inherit a clean environment at great inconvenience to ourselves? Do animals have the right 
not to be slaughtered by us for food? Do convicted criminals have the right to vote in elections? Do workers in emergency services have the right to strike? Do children have the right to self-determination?

What is interesting and important about this type of dispute is that it can occur even between people sharing a culture and sharing a moral framework. We would expect disputants from different cultures to have deep disagreements (although many of these would also, I suspect, finally come down to the same fault lines), but within a culture, where people would expect that their shared background would make discussion easy and fruitful, this type of debate appears to be intractable. It is still quite a step, however, to Fogelin's conclusion that such disagreements are 'not subject to rational resolution' (2005: 11). If one side of the dispute can be shown to be based on a contradictory or nonsensical belief, for example, then the debate may be amenable to a rational solution, even if one disputant clings to an irrational conclusion. That might depend on whether we perceive the debate as being the dialogue between two individuals or the propositional content of what they are saying. An issue has been settled rationally when it has been shown that a rational agent would accept one or other solution: if by deep disagreement we mean only disagreements with irrational people then they are rather less interesting.

The establishment of a set of common practices is, as David Godden has said, something which comes before argumentation can even take place - if one individual has no practice of discussion then no disagreement in the argumentational sense can occur because there is no attempt at argument. This leads to the claim that those elements missing in cases of deep disagreement 'are preparatory to argumentation; they are not a kind of (sustained) argumentation, but are rather a set of practices in which argumentation takes its place' (Godden 2011: 1). This is all very well, but it doesn't seem to be the case with Fogelin's examples, where the discussion has progressed a certain distance quite happily. Indeed, as Godden himself pointed out in an earlier paper 'it would seem that disagreement is only possible where agreement is also possible' (Godden \& Brenner 2010: 46) meaning that if the sets of argumentation practices do not match, there is no disagreement, and disagreements like those in the examples, can't be the result of such differences. The authors go on to suggest that deep disagreements are found where differing concepts meet, that they 'tend to occur on the fringes of understanding' (2010: 50), but this is something of a fudge: either disagreement pre-supposes the possibility of agreement or it doesn't; either the frameworks are sufficiently alike to produce agreement/disagreement, or they are not. 


\section{Martin Hinton}

Finocchiaro when setting out Fogelin's argument attributes to him the view that deep disagreements occur 'when the contending parties do not share any relevant beliefs, preferences, or resolution procedures' (2011: 3). This seems to be going too far. In Fogelin's examples the disputants do likely share many relevant beliefs, preferences, and, indeed practices: a general preference for life over death, a belief in the freedom of the individual, perhaps, a respect for the opinion of others and an understanding of burdens of proof, they simply do not share one particular belief, about the unborn having immortal souls from the moment of conception. In this case, that belief is likely to be part of a wider system of belief based on the teachings of a religious group, but that does not have to be the case. And, if we take the existence of these beliefs as preliminaries to the conduct of an argument, as part of a necessary framework in which that argument can take place, then it seems very unlikely we shall ever find a pair of people who are able to engage in argument, a pair whose relevant beliefs are all the same. I would suggest that the role of argumentation in many cases is simply to find the point at which those beliefs diverge, and, if they turn out to be unsupported by evidence or argument, one party may either change his belief or accept that his position cannot be rationally defended. As Lugg (1986) has suggested, this process enables the establishment of a good deal of common ground before the point of divergence is reached. Sensible people debating abortion laws are able to conduct that debate precisely because they do share a set of practices for argument and they quickly and rationally reach the conclusion that the crux of the debate is what status should be given to a foetus, even if they then discover that their views diverge at that point. It would be very odd to state that no argument had taken place in this case. The same is true in theology, since arguments for the existence of God, for example, have not generally been considered rationally convincing, the wise believer soon falls back on the position that his belief is a question of faith not reason. At this point the disagreement vanishes, since both parties can agree that the belief in question is not rationally supported, and that is all argument can do in any case. It is, however, argument that has allowed the parties to reach this stage. The great philosophical theologians of the past spent so much time designing arguments for the existence of God precisely because they believed in the process of rational argumentation just as much as they believed in the divine.

I share, then, the scepticism of Harvey Siegel over the existence of deep disagreement. Whatever beliefs the parties have, no matter how fundamental to their view of the world, they can either be rationally defended or 
they cannot. As he puts it: 'the beliefs and propositions involved in such allegedly deep disagreements [are] open to critical scrutiny and evaluation' (Siegel 2013: 21). If a belief is not open to such scrutiny, if one disputant claims that his belief is somehow beyond the reach of reason, that is tantamount to accepting that the belief, and any conclusions based on it, are unreasonable. This might also be characterised as a burden of proof fallacy where one party refuses to recognise the necessity for giving evidence/reasons for a statement made within his argument. Committing such a fallacy doesn't mean the argument has ended in disagreement, rather, that one party has forfeited his position by breaking the rules of engagement (see the work of van Eemeren \& Gootendorst, summarised in 2004). Where I refer to deep disagreements below, then, it is to the type of disagreement Fogelin cites, not to what I agree to be irresolvable clashes of frameworks, although I do not wholly rule out the possibility of such disagreements existing, particularly between people whose conceptions of reason are thoroughly alien to one another. There is, of course, a great deal more to discuss on this issue, but as it isn't the focus of my paper, having outlined my position, I should like to get on.

There is, I believe, another way of interpreting the disputes in Fogelin's examples: not as questions of who possesses rights as a morally significant being, but simply as reflections of differing priorities. In the case of abortion, one side may put forward what, for want of a better name, we might call the feminist argument. On this view, the advocate for abortion does not deny moral rights to the foetus, but holds that the pregnant woman's right to control over her own body is fundamental and cannot be denied: in short, whatever rights the foetus may have, the woman's right to self-determination is the priority. And again, we may accept that groups can have a right to justice when other members of the same group have been wronged, but still believe that the right of innocent individuals to fair treatment, whatever group they belong to, is the priority in any given case.

At first sight, this might not look like a great step forward, we might think it is just a different way of wording the same debate; but there is something of use to argumentation theorists here. Firstly, I think that most of the deep disagreements I listed above come into this class, since there are, I suppose, rather few people who would claim that animals, foetuses or children have no rights whatsoever, only that their rights are a lower priority than those of some other set of individuals. This suggests that apparently deep disagreements, as Fogelin characterises them, may not be necessarily absolute disagreements, but more a question of ordering. This 


\section{Martin Hinton}

could mean that a debate which appears to have run aground and exhausted the methods of normal discussion, might be able to float off again into an ordering exercise, where it becomes quite possible to demand reasons for the placing of one moral consideration over another. That does not mean, of course, that such a discussion will necessarily be fruitful, but it does provide a way to move forward, and it will be suggested below that other types of apparent stalemate in argumentation might be overcome by engaging in an ordering exercise, while accepting that the apparently contradictory views are both reasonable.

Fogelin is at first cautious with his idea, noting that just because 'deep disagreements exist does not mean that they are common' (2005: 9), but by the end of his paper he suggests that 'not every disagreement is deep' (2005: 11), implying, perhaps, that rather many are, which I think is much closer to the truth, using his way of characterising them. There are shallow disagreements which can be solved through examination of the argument and its supporting evidence; but deep disagreements, involving morality and to whom it applies, disagreements in which one or other of the disputants is reluctant to properly examine his own assumptions because of their importance to him, are not only common, they form the basis of our never-ending political debate. Politics in modern democracies is the continual discussion of the importance of the rights of the community against the rights of the individual, and, while politicians may claim that their opponents don't care about certain sections of society, in reality the differences are generally only in their priorities.

\section{Expert Disagreement}

There are two ways in which expert opinion giving can lead to serious disagreement. There are disagreements between experts themselves, and there are disagreements caused by a layperson making an appeal to expert opinion. In the former case, it is to be hoped that in many fields, at least, anyone deserving the name expert (and who, if anyone, that might be is not a question I shall address here) will be fully signed up to certain resolution procedures: physicians who disagree will carry out more tests, lawyers will consult the relevant statutes, engineers will check their calculations. In these fields the resolution procedure is part of what must be known and practised by the expert in order that he may actually be an expert. All of these procedures refer back to the way in which knowledge is originally gained in this field. Differing predictions, between economic forecasters, say, cannot 
be treated as serious expert disagreement because there is no professional resolution procedure other than waiting for the future to occur. Economics has no way to gain knowledge about the future, so it could be said that there is no such thing as an 'expert' prediction in the sense that while experts may predict, they are not expert at doing so.

It is tempting to declare that one cannot be an expert in any given area unless one is capable of following a procedure in order to check one's own statements, and, by extension, compare them with the statements of others. I shall stop short of doing so as it would require a thorough and rigorous discussion of the precise nature of expertise and the status of the expert. Suffice it to say, I am not sure that deep disagreements resulting from incompatible belief frameworks could actually occur between experts. The influence of outside factors obviously effects the judgement and interpretation of facts made: where physicians differ over medical ethics it is not the medicine, in which they are experts, which causes the disagreement, but rather the ethics, in which they are not. That a readiness and ability to provide justification and evidence for one's claims, and to be able to compare them with the claims of others, using expertise only from the relevant field, is an essential part of being considered a genuine expert is a good start at a definition, but there I shall leave it.

The second type of disagreement is that which arises when a party makes an appeal to expert testimony which is not accepted by a second party. This rejection may come in the form of a refutation, denying that the expert opinion is good evidence, or a rebuttal, where the conflicting opinion of another expert is offered. In the first case, the discussion might look something like this:

A: Henry VIII was a strong swimmer. Professor Smith said so in our lecture.

B: Nonsense, Professor Smith is a joker/liar/expert on modern history not the Tudors.

Whichever objection $\mathrm{B}$ raises to the unfortunate Smith, there are, in this case at least, presumably, procedures which could be followed by A \& B to establish whether he was talking seriously, sincerely and within his field of expertise. These procedures are largely foreshadowed by the Critical Questions Douglas Walton lists with his argument scheme for appeal to expert opinion, a list which began as six general points, but in the expanded version stretches to a scarcely practical twenty-one (Walton et al. 2008: 92-93). Indeed, even with personal access to Smith and the chance to talk to his colleagues about him and his reputation in the field, it seems unlikely that 


\section{Martin Hinton}

A would be able to answer questions such as '6.2. Is there external evidence $[. .$.$] , can the expert deal with this adequately?' or indeed '5.1. Does A$ [the claim] have general acceptance in S [the field]?' If they were able to answer this question there wouldn't be any need to worry about Smith's opinion on the matter anyway.

There is an important point to be made here about the role of critical questions in general, and one which Walton's extended list seems to have ignored. His much simpler scheme for arguments from 'position to know' has just three critical questions, amounting to: Is she really in a position to know? Did she really say that? and, Is she lying? Even here it quickly becomes clear that whoever is proposing the argument cannot actually be expected to answer the questions. The only way to know if the source is lying would be to find out the truth of the matter in another way, and if we could do that there would be no need to bother with her testimony. The critical questions, then, serve the purpose of showing the arguers what assumptions are being made; some of those assumptions can be checked, others cannot. That is the nature of presumptive reasoning. If anyone putting forward a presumptive argument could actually answer every possible question concerning that argument they wouldn't be making any assumptions and the argument would not be presumptive. The original list of questions was much criticised, by Wagemans (2011) for example, but Walton et al.'s expanded list misses the point and attempts to provide a list of specific questions which we use to assess the practice of expertise employed by the putative expert, despite, presumably, knowing that this is a near-impossibility in reality.

This is one way, then, that a dispute may become insoluble. Even if the parties share a common framework for assessing the testimony of experts they may well be unable to put it into operation due to a lack of resources, knowledge or time. Since the burden of proof is presumably on A to show that his expert is a reliable one, B may happily declare the argument that Henry VIII was a strong swimmer because Professor Smith says so to have been refuted. Yet it seems very likely that A will not be satisfied by this. Is it really possible that two people could share exactly the same standards and procedures for checking expert opinions? Perhaps if they are both dedicated disciples of Walton they will treat his list as the last word on the matter, but it seems very probable that A would turn to B and say, oh come on, Smith's a professor of history, that's good enough for me. Since the procedure for checking expertise is so controversial amongst scholars and so vague for

the general public, every appeal to expert opinion is in danger of leading to a deep disagreement. Can it ever be said that two people really share 
a procedure for checking such claims as part of a framework of beliefs which makes argument possible? Only if we take a very broad brush approach. In reality, there are no clear standards to apply, and even if there were, they would have to be different every time since clearly some expert opinions require stronger credentials than others.

If the response to the argument is a rebuttal, it may look like this:

A: Henry VIII was a strong swimmer. Professor Smith said so in our lecture.

B: Nonsense, I read in Jones's book that none of the Tudors could swim.

There are two courses now open to the disputants. Once they have checked, by asking other students and looking in the book, that the assertions were actually made in good faith, they can investigate the status of Smith and Jones separately to establish which, if either, of them is a reliable expert source, or they can accept that both are experts, but since they can't both be right, try to establish which of the two has the claim to a higher level of expertise. They try the first method and establish that Professor Smith is a history lecturer at their university giving courses on British Tudor history and Professor Jones is a history lecturer at a different institution who has written a book on the subject. A quick look at Google shows that both have published several papers in important journals on Tudor history. Indeed, as far as they are able to answer the questions Walton sets, the disputants find that both professors are credible expert sources and there is no reason to doubt the sincerity of either. Their internet search also returns only two results for enquiries about swimming Tudor monarchs: Professor Jones's book and Professor Smith's lecture notes ${ }^{1}$. What next? Most of the literature surrounding appeals to experts deals with establishing who is an expert, and once we establish that two people with conflicting opinions are both experts we come to an impasse.

There is, of course, an expansive literature on what can be done about the dispute if Smith and Jones are considered epistemological peers (see Christensen \& Lackey 2013 for a broad picture). This work focuses on what those peers themselves should do, but the discussion equally applies to what others should do when faced with their disagreement. One approach is to be a 'Conciliationist' and accept that 'the peer's disagreement gives one evidence that one has made a mistake in interpreting the original evidence, and that such evidence should diminish one's confidence in P' (Christensen 2009: 757); meaning it would be reasonable for both A \& B to hold their original positions more weakly than they did before they knew of the conflicting opinion, as it would seem that the opposing assertion deserves to be 


\section{Martin Hinton}

considered evidence for the opposing view. One way of being conciliatory is to give equal weight to the opinions and 'split the difference' (Christensen 2007, 2009), but various problems with this approach have been pointed out (Jehle \& Fitelson 2009). Even if it worked well with figures, in this case that would mean concluding that Henry VIII was a weak swimmer, something contrary to both scholars' assertions. Such a conclusion hardly seems reasonable. And while such conciliatory behaviour might be polite, it isn't obvious that it's rational. Kelly $(2005,2011)$ points out that if we are convinced of the rationality of our own thinking on the issue, there is no reason to abandon it simply because of the existence of an alternative view which does not explicitly provide a refutation of our argument. This is an interesting question for peers: how much should one doubt one's own rationality in the face of alternative conclusions from those one respects? However, given that A \& B have just been through the process of verifying the credibility of the two experts, it would be odd for them to simply abandon one because they had seen the other one first. The conclusion which they have brought to the argument is not their conclusion, so they have no implicit reason to stand by its rationality. A more promising suggestion is that they should, following Feldman (2006), suspend judgement. Both A \& B can accept that they don't really know whether Henry VIII could swim or not. Should they also conclude that Smith and Jones don't really know either? Would Smith and Jones accept that? They might, if they accept that they are, in fact, epistemic peers. Suppose, however, that A \& B accept that they cannot make an absolute judgement, but would like to know which view is more likely. This, after all, is the point of defeasible argumentation anyway, and we often employ it in situations where sitting on the fence is, for practical reasons, not an option.

The concept of the epistemic peer has much in common with the concept of the arguers with a shared framework: it works from a distance, but doesn't stand up to a very close examination. Just as every pair of arguers will have some differing beliefs and preferences, which they can only discover through the process of argument, so every epistemological pair will have some differences in knowledge, ability, or exposure to the evidence. Looked at in a wide perspective, the idea of individuals being peers is very useful and is certainly in everyday use. We all listen with respect to the views of those we consider roughly as qualified as we are, even if those views are wildly different to our own, but in the case of a serious and exactly defined dispute, we are likely to look more closely before accepting that conflicting view as equal in weight to our own. And we are also likely to look more 
closely into the relative credibility of those whose opinions we were inclined to take on trust, but have now been found to be in conflict.

So, A \& B then try the second method, but even if they are disciples of Walton or any of the other argumentation scholars who have addressed the point, they find there is little to guide them. Still, as is the case with most humans, they are actually quite skilled at comparing the merits of different cases and deciding which is the better option. It is obvious to them at once that even if both their sources are experts, one may be more expert than the other. So, instead of asking questions to establish whether or not an individual should be considered an expert, they begin to build a series of criteria by which they can rank experts. This proves easier than expected because they have been sub-consciously ranking conflicting sources of information all their lives. They both find it easy to accept that both Smith and Jones are better placed than they are to make assertions on the abilities of Henry VIII, and being, somewhat unusually, rational people they make no special attempt to champion their own source as the better one. The hard part is in determining which of Smith and Jones should be rated more highly as a source. Naturally, they avoid questions which they could not possibly answer such as how well the two scholars generally deal with evidence, and focus on information in the public domain. It doesn't take them long to see that, on the evidence available to them, Jones deserves to be considered the better source: her book has been reviewed and praised by world famous scholars, her articles have been cited hundreds of times, often by Smith, she works at the most prestigious university in the country. A \& B decide that, on balance, they should form a weak belief that Henry VIII could not swim. None of that, however, affects Smith's status as an expert. By any normal standard he is an expert and his opinion on matters related to this field should generally be considered reliable. He simply isn't as good an expert as Jones.

\section{Epistemic hierarchy}

What disputants A \& B have done, something which is done all the time without too much thought or consideration, is to build an epistemological hierarchy. They have put themselves at the bottom, Smith much higher up, and Jones a trifle higher than Smith. An epistemological hierarchy is simply an ordering of individuals with respect to their likelihood of knowing the answer to any particular question, where question is understood in a very broad sense. An argument scheme for appeal to testimony via an episte- 
mological hierarchy - the concept of expert is unnecessary - would look like this:

1. A attests that $\mathrm{X}$ is true in field $\mathrm{F}$

2. A is higher in the epistemological hierarchy for field $F$ than any other available attestor

Therefore, I should accept that $\mathrm{X}$ is true.

There are a few points to be made about this scheme. Firstly, the word 'field' should not be understood as a traditional field of knowledge; it might be any area of any breadth, such as the quality of beer served in pubs along the high street or Ancient History. As the field narrows, the hierarchy may change, and it makes sense to narrow it as much as possible, always remembering that the layman may not be aware of the differences between related fields of knowledge or where the question at hand lies in respect of them. What is to constitute the field in any particular instance is for the disputants to decide. Secondly, I prefer the construction 'should accept that $\mathrm{X}$ is true' to possible alternatives since it seems to capture the essential reasonableness of that acceptance. Once a proposition has been accepted, it can be acted upon or used as the next step in further debate. Acceptance avoids some of the linguistic and philosophical baggage inherent in the concept of belief. If all the evidence suggests that my friend is a swindler, then I am bound by reason to accept that he is and act accordingly, notwithstanding the fact that I can't quite believe that it is true. Belief often has an emotional element, sometimes even a wilful disregard for the facts of the situation, where we continue to believe in spite of all evidence to the contrary. This principle also serves well in cases of peer, or perhaps near-peer, disagreement. If a colleague can be shown to be fairly placed more highly in the hierarchy than oneself, then one should, in all reasonableness, accept her opinion, even though it clashes with one's own, and at some level, one continues to believe that one is right, being more intimately familiar with the process by which one's own view was reached. This may well be no more than self-deception, over-confidence or other bias, probably it is, but one goes on believing even after giving way and accepting the conflicting view, for all practical purposes.

It is also worth pointing out that the hierarchy eliminates questions of the number of conflicting opinions, since the view of the highest placed individual prevails over the views of all those below, no matter how many they are even if they are all in agreement. It is often claimed that great leaps forward in science are usually made by an individual or small group going against the accepted understanding of the majority, and this may 
be given as a reason for not accepting consensus views such as those on global warming. By employing a hierarchy of knowledge, however, we have a system by which it can be shown why a particular maverick should be believed, against the mass of his colleagues, rather than just acknowledging that sometimes mavericks are right and everyone else is wrong so we shouldn't dismiss them.

Here, of course, it is essential to understand that any two, or more, disputants cannot be expected to form a perfect epistemic hierarchy and thus solve all their problems. The purpose of the ordering process is to give their debate a direction in which to go, and rather than trying to establish whether or not a particular source is an 'expert' or is 'in a position to know', they set out to position sources relative to one another in order to guide them to the view which they should accept. This process should reveal a good deal about the sources which will reflect on their reliability, but also bring to everyone's attention the fact that there is no strict division between good and bad sources, rather, there are sources which are better than other sources, and it is reasonable to accept the best one that one can find.

This is where the link to the discussion of deep disagreements becomes clear. If two disputants in Fogelin's abortion example attempt to produce a hierarchy of rights, rather than focus on the fact that they have a fundamental disagreement over the nature of the foetus, it is, admittedly, quite possible, even probable, that they will continue to disagree. However, by being pushed to explain why one of them places a woman's right to agency over her own body, and indeed her life, over the right to life of a foetus, and why the other prioritises the rights of the unborn, it is to be hoped that the two sides come to understand both their opponent's position and their own reasons for holding the position that they do better than they did at the outset. It may turn out, for example, that the anti-abortionist can cite only the authority of the Catholic church as support for her belief. The realisation that she is basing a preference for the rights of the foetus over those of women like herself only on the say so of an entirely patriarchal organisation with an arguably dubious record on moral practice itself, might cause her to reconsider. Similarly, the pro-choice advocate might discover that she cannot actually think of a good reason why the rights of the mother trump those of the foetus and that she has, in fact, been clinging to a belief in abortion rights as part of her identity as a modern woman, as described by the magazines she reads and the society with which she mixes. What is important is that while such realisations might equally well not occur, the idea that a fundamental 'framework' disagreement allows of no further discussion, does not even give them the chance. 


\section{Martin Hinton}

The negotiation process of establishing the hierarchy is less confrontational and requires no-one to abandon their belief, only to reconsider how it ranks against other considerations. And the same is true for the appeal to experts examples: no-one is forced to abandon the evidence they have raised, no-one is dismissed as lacking credibility; one source, however, is elevated to a higher position and accepted. At least, a co-operative examination of the sources takes place, even if a final agreement on the hierarchy cannot be reached.

\section{N O T E}

1 Actually, Google reveals nothing at all about the king's aquatic abilities.

\section{R E F E R E N C E S}

Christensen, D. (2007). Epistemology of disagreement: the good news. Philosophical Review, 116(2), 187-217.

Christensen, D. (2009). Disagreement as Evidence: The Epistemology of Controversy. Philosophy Compass 4/5 (2009): 756-767.

Christensen, D. \& Lackey, J. (Eds.) (2013). The Epistemology of Disagreement: New Essays. Oxford: Oxford University Press.

van Eemeren, F. \& Grootendorst, R. (2004). A systematic Theory of Argumentation. Cambridge: Cambridge University Press.

Feldman, R. (2006). Epistemological puzzles about disagreement. In. S Heatherington, ed., Epistemology Futures (pp. 216-236). New York: Oxford University Press.

Finocchiaro, M. (2011). Deep disagreements: A meta-argumentation approach. In Zenker, F. (ed.). Argumentation: Cognition and Community. Proceedings of the 9th International Conference of the Ontario Society for the Study of Argumentation (OSSA). http://scholar.uwindsor.ca/ossaarchive/OSSA9/ papersandcommentaries/31.

Fogelin, R. (2005). The logic of deep disagreements. Informal Logic 25(1), 3-11.

Godden, D. (2011). Commentary on "Deep disagreements: A meta-argumentation approach" by Maurice Finocchiaro. In Zenker, F. (ed.). Argumentation: Cognition and Community. Proceedings of the 9th International Conference of the Ontario Society for the Study of Argumentation (OSSA). http://scholar. uwindsor.ca/ossaarchive/OSSA9/papersandcommentaries/31

Godden, D. \& Brenner, W. (2010). Wittgenstein and the logic of deep disagreement. Cogency vol. 2, no. 2, 41-80. 
Lugg, A. (1986). Deep disagreement and informal logic: No cause for alarm. Informal Logic 8.1: 47-51.

Jehle, D. \& Fitelson, B. (2009). What is the "Equal Weight View"? Episteme 2009, 280-293.

Kelly, T. (2005). The epistemic significance of disagreement. In T. S. Gendler \& J. Hawthorne (Eds.), Oxford Studies in Epistemology 1 (pp. 167-196).

Kelly, T. (2011). Peer Disagreement and Higher Order Evidence. In A. Goldman \& D. Whitcomb (Eds.) Social Epistemology: Essential Readings. Oxford: Oxford University Press.

Siegal, H. (2013). Argumentation and the epistemology of disagreement. OSSA Conference Archive. Paper 157. http://scholar.uwindsor.ca/ossaarchive/OS SA10/papersandcommentaries/157.

Wagemans, J. (2011). The Assessment of Argumentation from Expert Opinion. Argumentation 25: 329-339.

Walton, D., Reed, C. \& Macagno, F. (2008). Argumentation Schemes. New York: Cambridge University Press. 